\title{
Corrigendum: Roadmap towards justice in urban climate adaptation research
}

Linda Shi, Eric Chu, Isabelle Anguelovski, Alexander Aylett, Jessica Debats, Kian Goh, Todd Schenk, Karen C. Seto,

David Dodman, Debra Roberts, J. Timmons Roberts \& Stacy D. VanDeveer

Nature Climate Change 6, 131-137 (2016); published online 27 January 2016; corrected after print 26 April 2016

In the version of this Perspective originally published, it was not acknowledged that this work was contributing to the ICTA 'Unit of Excellence.' This correction has been made to the online version. 